\title{
Prophylactic efficacy of probiotics on travelers' diarrhea: an adaptive meta-analysis of randomized controlled trials
}

\author{
Jong-Myon Bae \\ Department of Preventive Medicine, Jeju National University School of Medicine, Jeju, Korea
}

\begin{abstract}
OBJECTIVES: The 2017 guideline for the prevention of travelers' diarrhea (TD) by the International Society of Travel Medicine suggested that 'there is insufficient evidence to recommend the use of commercially available prebiotics or probiotics to prevent or treat TD.' However, a meta-analysis published in 2007 reported significant efficacy of probiotics in the prevention of TD (summary relative risk [sRR], $0.85,95 \%$ confidence interval [CI], 0.79 to 0.91 ). This study aimed to synthesize the efficacy of probiotics on TD by updating the meta-analysis of double-blind, placebo-controlled, randomized human trials.

METHODS: The search process was conducted by the adaptive meta-analysis method using the 'cited by' and 'similar articles' options provided by PubMed. The inclusion criteria were double-blind, placebo-controlled, randomized human trials with hypotheses of probiotics as intervention and TD as an outcome. The adaptive meta-analysis was conducted using Stata software using the csi, metan, metafunnel, and metabias options.
\end{abstract}

RESULTS: Eleven articles were selected for the meta-analysis. The sRR was 0.85 (95\% CI, 0.79 to 0.91 ) and showed statistical significance. There was no heterogeneity ( $\mathrm{I}$-squared $=28.4 \%$ ) and no publication bias.

CONCLUSIONS: Probiotics showed statistically significant efficacy in the prevention of TD.

KEY WORDS: Probiotics, Diarrhea, Randomized controlled trials, Meta-analysis

\section{INTRODUCTION}

While environmental hygiene has improved more than before, travelers' diarrhea (TD) remains one of the most important public health issues in the international community as more and more people travel around the world [1]. Although it might be possible to consider administering antibiotics to prevent TD, given that bacteria account for more than $80 \%$ of the pathogens that cause

\section{Correspondence: Jong-Myon Bae}

Department of Preventive Medicine, Jeju National University School of Medicine, 102 Jejudaehak-ro, Jeju 63243, Korea

E-mail:jmbae@jejunu.ac.kr

Received: Aug 1, 2018 / Accepted: Aug 29, 2018 / Published: Aug 29, 2018

This article is available from: http://e-epih.org/

(C) This is an open-access article distributed under the terms of the Creative Commons Attribution License (http://creativecommons.org/licenses/by/4.0/), which permits unrestricted use, distribution, and reproduction in any medium, provided the original work is properly cited.

(C) 2018, Korean Society of Epidemiology
TD [2], this causes the problem of antibiotic resistance [3]. According to the guideline published in 2017 by the International Society of Travel Medicine (ISTM) [1], antibiotics are contraindicated for the prevention of TD among the general population.

The guideline also states that there is insufficient evidence to recommend the use of commercially available prebiotics or probiotics to prevent or treat TD. Among 2 meta-analysis studies cited in the guideline [4,5], Sazawal et al. [4] selected 4 articles that published randomized, placebo-controlled trial results [6-9], and revealed that there was no significant difference in prevention efficacy (summary relative risk [sRR], 0.92; 95\% confidence interval [CI], 0.80 to 1.06). However, McFarland's study [5], which was published a year later in 2007, added three articles to the four aforementioned articles, selected 7 in total [6-12], and reported that probiotics were effective in preventing TD (sRR, $0.85 ; 95 \% \mathrm{CI}$, 0.79 to 0.91 ). In addition, a meta-analysis published in 2012 [13] included only 4 articles selected by Sazawal et al. [4] and demonstrated that their systemic review was incomplete. 
Accordingly, what needs to be considered first and foremost for this discrepancy regarding the prevention efficacy of probiotics against TD between meta-analysis results and guidelines is that a systematic review should be adapted. The purpose of this study was to reevaluate the prevention efficacy of probiotics against TD using an adaptive meta-analysis.

\section{MATERIALS AND METHODS}

Given that this study updated the existing meta-analysis, an adaptive meta-analysis was conducted [14]. This involved creating a list that synthesized articles by 'cited by' and 'similar articles' pro-

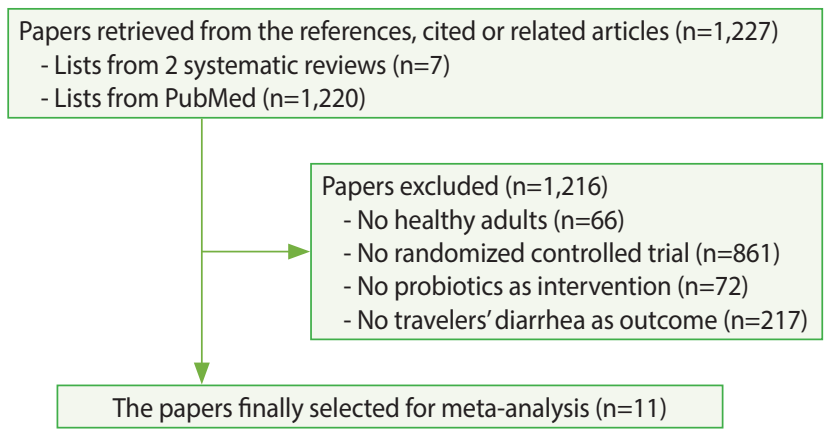

Figure 1. Flow chart of articles' selection.

Table 1. Summaries of 11 selected articles for adaptive meta-analysis

\begin{tabular}{|c|c|c|c|c|c|c|c|}
\hline \multirow{2}{*}{ First author [RN] } & \multirow{2}{*}{$\begin{array}{c}\text { Publication } \\
\text { year }\end{array}$} & \multicolumn{2}{|c|}{ Treatment } & \multicolumn{2}{|c|}{ Placebo } & \multirow{2}{*}{$\begin{array}{c}\text { RR } \\
(95 \% \mathrm{Cl})\end{array}$} & \multirow{2}{*}{ Probiotics } \\
\hline & & $\mathrm{n}$ & TD & $\mathrm{n}$ & TD & & \\
\hline de dios Pozo-Olano [6] & 1978 & 26 & 9 & 24 & 7 & $1.19(0.52,2.69)$ & L. acidophilus \& L. bulgaricus \\
\hline Black [10] & 1989 & 47 & 20 & 47 & 33 & $0.61(0.41,0.89)$ & Mixed \\
\hline Kollaritsch [19] & 1989 & 1,148 & 437 & 712 & 321 & $0.84(0.76,0.94)$ & S. boulardii \\
\hline Oksanen [7] & 1990 & 373 & 153 & 383 & 178 & $0.88(0.75,1.04)$ & L. rhamnosus GG \\
\hline Kollaritsch [12] & 1993 & 655 & 208 & 361 & 141 & $0.81(0.69,0.96)$ & S. boulardii \\
\hline Katelaris [8] & 1995 & 181 & 45 & 101 & 24 & $1.05(0.68,1.61)$ & L. acidophilus \& L. fermentum \\
\hline Hilton [9] & 1997 & 126 & 5 & 119 & 9 & $0.52(0.18,1.52)$ & L. rhamnosus GG \\
\hline Briand [16] & 2006 & 79 & 30 & 72 & 22 & $1.24(0.79,1.95)$ & L. acidophilus \\
\hline Drakoularakou [17] & 2010 & 81 & 19 & 78 & 30 & $0.61(0.38,0.99)$ & $\mathrm{GO}$ \\
\hline Virk [3] & 2013 & 94 & 52 & 102 & 55 & $1.03(0.79,1.32)$ & Mixed \\
\hline Hasle [18] & 2017 & 167 & 32 & 167 & 48 & $0.67(0.45,0.99)$ & GO \\
\hline
\end{tabular}

RN, reference number; TD, travelers' diarrhea; RR, relative risk; Cl, confidence interval; L, Lactobacillus; S, Saccharomyces; GO, galacto-oligosaccharide.

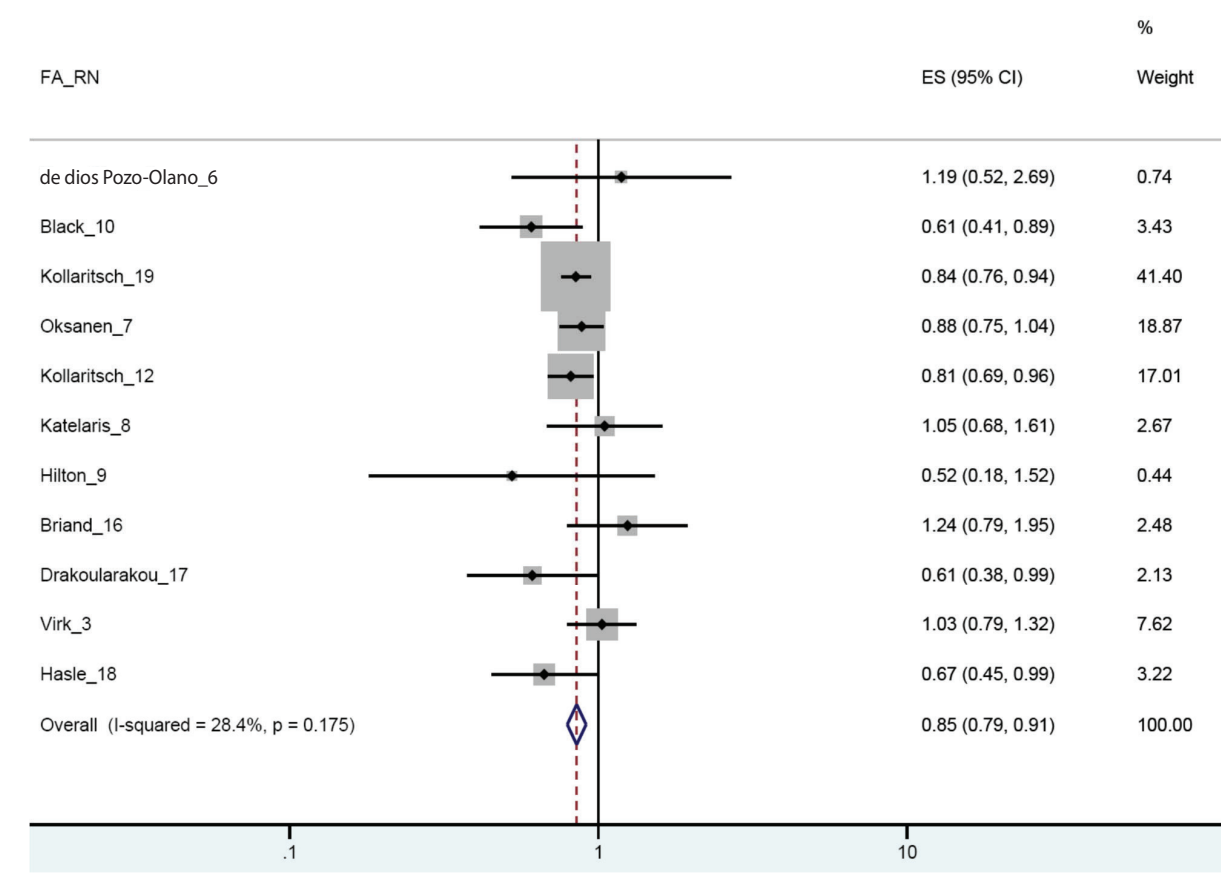

Figure 2. Forest plot from 11 selected articles. FA_RN, first author \& reference number; ES, effect size. 
vided by PubMed (https://www.ncbi.nlm.nih.gov/pubmed/) for 2 meta-analysis studies $[4,5]$ and their selected seven randomized trial articles [6-12].

The following are exclusion criteria applied to the synthesized list: (1) the subjects were not healthy adults, (2) the study design was not a randomized, placebo-controlled trial, (3) the treatment intervention was not a probiotic, and (4) the outcome was not the efficacy of TD prevention.

Data regarding the total number of subjects and the number of the subjects who developed TD in treatment and control groups were extracted from the finally selected articles. By applying the command csi in the Stata/SE version 14 (StataCorp., College Station, TX, USA), the relative risks (RRs) and 95\% CIs were calculated for each article, after which a meta-analysis was conducted by calculating the sRR using the command metan [15]. Heterogeneity among the articles was assessed using the I-squared value (\%), and this study applied a fixed effect model when there was no heterogeneity. To identify the existence of publication bias, this study applied the options metafunnel and metabias.

\section{RESULTS}

As of July 27, 2018, a list of 1,227 articles was created from the search, and 11 articles were finally selected when the four exclusion criteria were applied (Figure 1) [3,6-10,12,16-19]. Four more articles were selected in addition to the 7 articles chosen in the 2 existing meta-analysis studies. Furthermore, among the 7 articles selected in McFarland's 2007 study [5], the article published by Kollaritsch et al. [11] was replaced by another article published by Kollaritsch \& Wiedermann [19], which contained more detailed information. Table 1 shows the RRs and 95\% CIs calculated based on information extracted from 11 articles.

Among the 11 selected articles, only two published since 2006 $[16,18]$ presented intention-to-treat (ITT) and per-protocol (PP) separately. In this regard, when the RRs calculated by PP only were

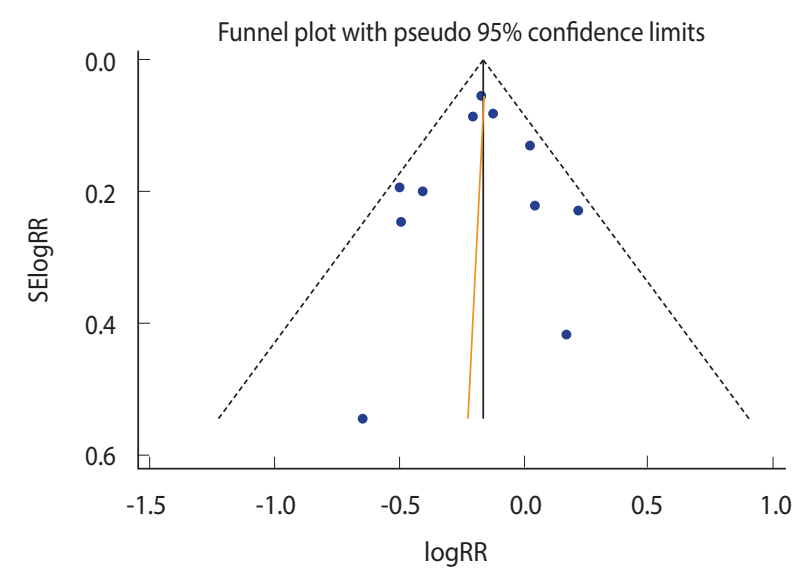

Figure 3. Funnel plot (Begg's test: $p=0.94$; Egger's test: $p=0.83$ ). $S E_{\text {, }}$ standard error; RR, relative risk. applied, there was efficacy in TD prevention while homogeneity was ensured (I-squared $=28.4 \%$; $\mathrm{sRR}, 0.85 ; 95 \% \mathrm{CI}, 0.79$ to 0.91 ) (Figure 2). Statistical significance was ensured even when the value was replaced by ITT (sRR, 0.86; 95\% CI, 0.80 to 0.92) (not shown). As a result of funnel plot, Begg's test, and Egger's test, it was confirmed that there was no publication bias (Figure 3).

\section{DISCUSSION}

While the 2017 ISTM guideline [1] stated that there was insufficient evidence regarding the efficacy of probiotics in the prevention of TD, these results added evidence that probiotics had efficacy in preventing TD. Compared to McFarland's effect size of 0.85 (95\% CI, 0.79 to 0.91 ) from the seven selected articles [5], that of this study, which added 4 more articles, showed a similar level (sRR, $0.85 ; 95 \%$ CI, 0.79 to 0.91 ). Given that 2 out of the 4 added articles $[3,16]$ produced the same effect size despite the lack of statistical significance in their RR, it provides evidence for the efficacy of probiotics in preventing TD.

As probiotics are already known to be effective for the management of acute infectious diarrhea and antibiotic-associated diarrhea [20], this meta-analysis in which they also showed prevention efficacy on TD would make it more necessary to conduct a follow-up study in the future. Nonetheless, considering that there were different types of probiotics that also differed in their routes of administration, the observation period varied among the articles, and the results were not classified according to PP and ITT, it would be necessary to ensure more consistency in performing clinical trials.

\section{CONFLICT OF INTEREST}

The author has no conflicts of interest to declare for this study.

\section{SUPPLEMENTARY MATERIALS}

Supplementary Material: Korean version is available at (http:// www.e-epih.org/).

\section{ORCID}

Jong-Myon Bae: https://orcid.org/0000-0003-3080-7852

\section{REFERENCES}

1. Riddle MS, Connor BA, Beeching NJ, DuPont HL, Hamer DH, Kozarsky P, et al. Guidelines for the prevention and treatment of travelers' diarrhea: a graded expert panel report. J Travel Med 2017;24:S57-S74.

2. Gascón J. Epidemiology, etiology and pathophysiology of traveler's diarrhea. Digestion 2006;73 Suppl 1:102-108.

3. Virk A, Mandrekar J, Berbari EF, Boyce TG, Fischer PR, Kasten $\mathrm{MJ}$, et al. A randomized, double blind, placebo-controlled trial of 
an oral synbiotic (AKSB) for prevention of travelers' diarrhea. J Travel Med 2013;20:88-94.

4. Sazawal S, Hiremath G, Dhingra U, Malik P, Deb S, Black RE. Efficacy of probiotics in prevention of acute diarrhoea: a meta-analysis of masked, randomised, placebo-controlled trials. Lancet Infect Dis 2006;6:374-382.

5. McFarland LV. Meta-analysis of probiotics for the prevention of traveler's diarrhea. Travel Med Infect Dis 2007;5:97-105.

6. de dios Pozo-Olano J, Warram JH Jr, Gómez RG, Cavazos MG. Effect of a lactobacilli preparation on traveler's diarrhea. A randomized, double blind clinical trial. Gastroenterology 1978;74:829830.

7. Oksanen PJ, Salminen S, Saxelin M, Hämäläinen P, Ihantola-Vormisto A, Muurasniemi-Isoviita L, et al. Prevention of travellers' diarrhoea by Lactobacillus GG. Ann Med 1990;22:53-56.

8. Katelaris PH, Salam I, Farthing MJ. Lactobacilli to prevent traveler's diarrhea? N Engl J Med 1995;333:1360-1361.

9. Hilton E, Kolakowski P, Singer C, Smith M. Efficacy of Lactobacillus GG as a diarrheal preventive in travelers. J Travel Med 1997; 4:41-43.

10. Black FT, Anderson PL, Orskov J, Orskov F, Gaarslev K. Laulund S. Prophylactic efficacy of Lactobacilli on traveler's diarrhea. Travel Med 1989;7:333-335.

11. Kollaritsch H, Kremsner P, Wiedermann G, Scheiner O. Prevention of traveller's diarrhea: comparison of different non-antibiotic preparations. Travel Med Int 1989;6:9-17.

12. Kollaritsch H, Holst H, Grobara P, Wiedermann G. Prevention of traveler's diarrhea with Saccharomyces boulardii. Results of a placebo controlled double-blind study. Fortschr Med 1993;111:152156 (German)

13. Ritchie ML, Romanuk TN. A meta-analysis of probiotic efficacy for gastrointestinal diseases. PLoS One 2012;7:e34938.

14. Bae JM, Kim EH. Citation discovery tools for conducting adaptive meta-analyses to update systematic reviews. J Prev Med Public Health 2016;49:129-133.

15. Shim SR, Shin IS, Bae JM. Intervention meta-analysis using STATA software. J Health Info Stat 2016;41:123-134 (Korean).

16. Briand V, Buffet P, Genty S, Lacombe K, Godineau N, Salomon J, et al. Absence of efficacy of nonviable Lactobacillus acidophilus for the prevention of traveler's diarrhea: a randomized, doubleblind, controlled study. Clin Infect Dis 2006;43:1170-1175.

17. Drakoularakou A, Tzortzis G, Rastall RA, Gibson GR. A doubleblind, placebo-controlled, randomized human study assessing the capacity of a novel galacto-oligosaccharide mixture in reducing travellers' diarrhoea. Eur J Clin Nutr 2010;64:146-152.

18. Hasle G, Raastad R, Bjune G, Jenum PA, Heier L. Can a galactooligosaccharide reduce the risk of traveller's diarrhoea? A placebo-controlled, randomized, double-blind study. J Travel Med 2017. doi: https://doi.org/10.1093/jtm/tax057.

19. Kollaritsch HH, Wiedermann G. Prevention of traveler's diarrhea: a double-blind randomized trial with Saccharomyces cerevisiae Hansen CBS 5926. Travel Med 1989:7:328-332.

20. Wilkins T, Sequoia J. Probiotics for gastrointestinal conditions: a summary of the evidence. Am Fam Physician 2017;96:170-178. 